Madrygal. Revista de Estudios Gallegos

ISSN: 1138-9664

\title{
La mujer emigrante y exiliada como custodia de la memoria histórica gallega. El caso del proceso a José Mejuto Bernárdez, republicano fusilado en $1937^{1}$
}

\author{
Ana Paula Mejuto Soba²; Olivia Rodríguez González ${ }^{3}$
}

Recibido: 31 de marzo de 2016 / Aceptado: 2 de decembro de 2016

Resumen. El mecánico naval de Cangas do Morrazo, José Mejuto Bernárdez (1906-1937), se vio incurso en un proceso militar a raíz de la represión política en Galicia durante la guerra civil española (1936-1939). Antes de ser fusilado, escribió una treintena de cartas en la cárcel. Hasta su publicación en 2015, fueron custodias de esta memoria epistolar las mujeres de su familia, que viajaron de Galicia hacia Buenos Aires en una emigración que encubría una modalidad máis de exilio republicano. Con las herramientas de la Retórica, se hace una lectura confrontada de los momentos más relevantes del proceso tal como aparecen en el Expediente del Consejo de Guerra y en las cartas que Mejuto envía desde prisión.

Palabras clave: Retórica; memoria epistolar; guerra civil española; Consejo de Guerra; exilio femenino.

\section{[gl] A muller emigrante e exiliada como custodia da memoria histórica galega. $\mathrm{O}$ caso do proceso a José Mejuto Bernárdez, republicano fusilado en 1937}

Resumo. O mecánico naval de Cangas do Morrazo, José Mejuto Bernárdez (1906-1937), viuse incurso nun proceso militar a raíz da represión política en Galicia durante a guerra civil española (1936-1939). Antes de ser fusilado, escribiu unha trintena de cartas no cárcere. Ata a súa publicación en 2015, foron custodias desta memoria epistolar as mulleres da súa familia, que viaxaron a principios dos anos 50 de Galicia a Buenos Aires nunha emigración que agochaba unha modalidade máis do exilio republicano. Coas ferramentas da Retórica, lévase a cabo unha lectura confrontada dos momentos máis relevantes do proceso tal como aparecen no expediente do Consello de Guerra e nas cartas que Mejuto envía desde a cadea.

Palabras chave: Retórica; memoria epistolar; guerra civil española; Consello de Guerra; exilio feminino.

\section{[en] The Emigrant and Exiled Woman as Custody of Galician Historical Memory. The Case of the Process to José Mejuto Bernárdez, Republican Shot in 1937}

\begin{abstract}
José Mejuto Bernárdez (1906-1937), a ship mechanic from Cangas do Morrazo, was involved in a military process as a result of the political repression in Galicia during the Spanish Civil War (1936-1939). Before being shot, he wrote about thirty letters from prison. His female relatives became relevant as guardians of the memory; they travelled in the early 50s from Galicia to Buenos Aires, in a sort of migration hiding another form of republican exile. With the aid of Rhetoric we will carry out a confronted reading of the most relevant moments of the process as shown both in the documents of the War Council and in the letters that Mejuto sent from prison.
\end{abstract}

Keywords: Rethoric; Epistolary Memory; Spanish Civil War; War Council; Female Exile.

Sumario. 1. Preliminares. 2. José Mejuto Bernárdez y la cadena femenina de transmisión de su memoria epistolar. 3. Proceso y archivo: los Expedientes. 4. Lectura del proceso en el Expediente del Consejo de Guerra y en las cartas de

Este trabajo se ha llevado a cabo en el marco de los proyectos de investigación "Ex-sistere: La movilidad de las mujeres en las literaturas gallega e irlandesa contemporáneas" (FFI 2012-35872, 2013-2016) y "Eco-ficción. Discursos emergentes sobre mujer y naturaleza en Galicia e Irlanda" (FEM2015-66937-P, 2016-2018).

2 Universidad Nacional de San Martín, Departamento de Humanidades.

E-mail: anamejuto@yahoo.com.ar

3 Universidade da Coruña, Departamento de Filoloxía Española e Latina.

E-mail: olivia@udc.es 
José Mejuto Bernárdez. 5. La doble narración del proceso. 6 Detención. 7. Informe de la Guardia Civil de Cangas con las declaraciones de tres guardias municipales. 8 . Más informes negativos e infructuosas declaraciones de los testigos de la defensa. 9. Sentencia. 10. Conclusión. 11. Referencias bibliográficas.

Como citar: Mejuto Soba, A. P. e O. Rodríguez González (2017): "La mujer emigrante y exiliada como custodia de la memoria histórica gallega. El caso del proceso a José Mejuto Bernárdez, republicano fusilado en 1937”, Madrygal. Revista de Estudios Gallegos 20 (Núm. especial), pp. 165-177.

\section{Preliminares}

Este trabajo es el nuevo resultado de una investigación que se remonta a mayo de 2012 , fecha del encuentro de las autoras en Buenos Aires (2012). Ana Paula Mejuto puso en conocimiento de Olivia Rodríguez la existencia de unas cartas de su abuelo fusilado por el ejército levantado contra la II República. La familia las había conservado a lo largo de los años en la emigración-exilio en Argentina. Por esa razón inician juntas un trabajo sobre memoria familiar y memoria pública de lo acontecido en Galicia a partir de la guerra civil, que han dado a conocer en diversas publicaciones y congresos y especialmente a través de la edición por Alvarellos en 2015 de las cartas de José Mejuto Bernárdez (Mejuto Bernárdez, 2015). Contaron las cartas con un prólogo de Xesús Alonso Montero, especialista en la II República y la guerra civil, y editor en 2009 de un volumen de cartas de republicanos condenados a muerte (Alonso Montero 2009). Desde la experiencia de sus muchos años de investigación sobre el tema, el prologuista quiso ponderar el valor del volumen con estas palabras: "son una página antológica de la epistolografía de los condenados a muerte de la Guerra Civil Española. Una obra, por otra parte, que debería ser libro de texto, en los institutos, en las clases de Historia, de Ética y de Literatura" (Alonso Montero 2015: 26).

Las autoras creen que ha llegado el momento de realizar una lectura contrastiva, por un lado, del Expediente de la causa en la que se vio involucrado Mejuto; y por otro, de las cartas en las que hace referencia a su proceso. Al contrastar dos textos sobre los mismos hechos pero confeccionados desde condiciones semióticas opuestas -las de la víctima y el victimario-, se ha pretendido dar al estudio del caso José Mejuto un nuevo enfoque: el del análisis textual comparado, con ayuda de las herramientas que proporciona la Retórica, un valioso legado clásico reactualizado desde el pasado siglo a través, entre otras disciplinas, de la teoría literaria.

\section{José Mejuto Bernárdez y la cadena feme- nina de transmisión de su memoria epistolar}

El cangués José Mejuto Bernárdez vivió muy unido a su madre Josefa, que queda viuda cuando él contaba dos años. Josefa se vuelve a casar con un primo también viudo y padre de cinco hijas, con las que José conviviría en Huelva, escenario de infancia que le deja una huella profunda. Nunca olvidaría el cariño de su segundo padre, que le animó a seguir desde adolescente el aprendizaje de un oficio que siempre le apasionó. Con su nueva hermana, Carmen, y su madre otra vez viuda, se muda a Vigo a principios de los años 20 y estudia mecánica naval en la Escuela Industrial de la ciudad. Con 22 años comienza a trabajar en los talleres Paulino Freire de Bouzas (Vigo).

Conoce a Alejandra Nogueiras Lagoa, canguesa de familia de industriales y armadores, y se casa con ella en San Andrés de Hío (Cangas) en 1930. Siguiendo los ritos sociales de la burguesía de la época, la prensa informa de la petición de mano y la boda. Gracias a ello, se sabe que la abuela de la novia, Alejandra Lagos Soliño y el periodista Ángel Bernárdez Rodríguez, tío de José, representan en la petición de mano a los ascendientes de los novios. Y que en la boda son testigos el primo de José, Ángel Bernárdez Losada, y Marcelino Moldes Rodal, el que será a partir de ahora su concuñado (El Pueblo Gallego 1930a, 1930b). Estos nombres irán después ligados a momentos cruciales de la historia procesal de José Mejuto.

Entre 1931 y 1936 nacen los cuatro hijos de la pareja: Isabel, Josefina, Fernando y Manuel. Reside la familia en Coia (Vigo). José Mejuto deja el trabajo en Paulino Freire cuando es elegido en la UGT delegado de Vigo en el Comité Nacional de La Federación de Obreros Metalúrgicos, y como tal, participa en reuniones de febrero de 1932 en Madrid (El Metalúrgico 1932a, 1932b).

En 1934, Alejandra Nogueiras se convierte en rica heredera tras la muerte de la abuela. Igual que sus hermanas lo son por sus respectivos cónyuges, ella es representada por su marido ante el Consejo de Familia, como 
establecen las normas legales de la época. En la reunión para el reparto de la herencia están presentes los que luego tendrán un papel decisivo en el proceso.

Ese año tiene lugar la revolución de octubre durante el llamado Bienio Negro, en que la derecha, que se ha presentado unida a las elecciones para formar el nuevo gobierno de la República, deshace los logros progresistas del gobierno anterior. La tensión domina el ambiente social, porque las clases obreras y campesinas se resisten al proceso involutivo. Se abren múltiples frentes, pero la revolución fracasa en algunas zonas o es reprimida con celeridad en otras, y solo triunfa en las cuencas mineras de Asturias. El aplastamiento de la revolución en esa zona es encargada al joven militar africanista Francisco Franco, que se hace acompañar de las fuerzas mercenarias del ejército colonial para reprimir a mineros y civiles, dejando un elevado número de muertos. La represión se extiende por todo el país y crece el número de desterrados y encarcelados (Fernández 2005).

Solo se sabe de José Mejuto en este periodo que a principios de 1935 abre un taller en el barrio de $\mathrm{O}$ Forte en Cangas, anexo a su vivienda en el predio que Alejandra Nogueiras ha heredado de la abuela. La nueva situacion económica de la familia le ha permitido ascender a autónomo y ser su propio patrono. Un día recibe a un cliente especial, el armador Manuel Moldes Iglesias, que le encarga la reparación de un barco de vapor. José Mejuto asume el abono de los materiales para llevarla a cabo. Manuel Moldes no querrá pagarlos y la factura va y viene hasta que el mecánico reclama la deuda por vía judicial. Las consecuencias para él serán terribles.

Tras el golpe militar, se declara la guerra en Cangas el 20 de julio de 1936. Agustín Jorge Echeverri, del Partido Radical y presidente de la Comisión Gestora del Ayuntamiento, ha convocado a las fuerzas políticas que quieran hacer frente a las tropas levantadas contra la II República. Los días 19 y 20 de julio se recogen armas y dinamita en el ayuntamiento para cargarlas en camiones y acudir a defender Pontevedra. El convoy es detenido en Marín por el ejército rebelde, y el alcalde y sus acompañantes son detenidos. Encausados en uno de los procesos más prolijos y ramificados de la guerra civil en Galicia, serán la mayoría de ellos fusilados.
La causa sigue abierta para incluir en ella a decenas de personas más a las que se quiere quitar de en medio. Una de ellas será José Mejuto Bernárdez, encarcelado en septiembre de 1937 al ser detenido en Vigo y encausado en un proceso abierto contra perseguidos políticos. Cuando la guardia civil de Cangas sea requerida para informar sobre él, sus enemigos, entre los que se encuentran sus cuñados falangistas Marcelino Moldes y Jesús Fraga, aprovecharán la ocasión para eliminarlo también. ¿De qué manera? Logrando involucrarlo en la causa donde se juzgan los sucesos en el Ayuntamiento al declararse el estado de guerra en Cangas el 20 de julio de 1936.

José Mejuto Bernárdez escribe continuamente desde la cárcel a su familia. En especial, a su mujer Alejandra. Cuando ella se embarque con los suyos a Argentina, harta del acoso político, llevará en la maleta las cartas que seguirá leyendo hasta la muerte y dejará en herencia a sus descendientes.

Esa herencia empezó a cobrar dimensión pública en los últimos años con la labor rememorativa de su nieta Ana Paula Mejuto. Ella es, por ahora, el último eslabón de esta cadena femenina de la memoria. Al hacerla pública, como una muestra más de los crímenes de guerra franquistas, se une a la lucha contra las deficiencias impuestas en la recuperación y transmisión de la memoria colectiva gallega y española.

\section{Proceso y archivo: los Expedientes}

José Mejuto Bernárdez se vio incurso, pues, en dos procesos. A los cuatro meses de su detencion, fue descartado del primero, Causa 1077/36. Contra Ramón Rey Fernández y otros por el delito de rebelión militar, donde su nombre no aparece por ninguna parte en los interrogatorios de los otros procesados. Por los informes de la Guardia Civil de Cangas, ya mencionados, y del alcalde y delegado de Orden Público en la villa, Óscar Boán y Callejas, terminará encartado en el segundo, Causa 790/36. Contra Agustín Jorge Echeverri y otros por el delito de auxilio a la rebelión militar.

Para comparar los dos relatos, el de José Mejuto y el del ejército sublevado y sus colaboradores, se acudirá al segundo expediente, que incorpora la documentación relativa a Mejuto desde su detención en Vigo el 20 de septiembre de 1936. Se trata de un voluminoso 
legajo de tapas carcomidas que contiene textos de tipo heterogéneo: desde instancias, solicitudes, circulares, atestados y otros formularios administrativos de la justicia militar, a informes de cumplimiento de la ley de fugas, cartas anónimas de denuncia, registro de declaraciones de testigos en la fase indagatoria del proceso, etc., etc. Es preciso distinguir entre la parte acumulativa de pruebas indagatorias, que es la de mayor extensión; y la información contenida en el relato del consejo de guerra y el fusilamiento de los condenados a muerte. Se tomarán algunas muestras de la primera parte y se centrará la atención en ciertos pasajes de la segunda.

Es paradójico que la finalidad pragmática de archivar este y otros consejos de guerra franquistas fuese dar carta de naturaleza legal, para la historia del futuro, a estas acciones judiciales. Hoy se accede a esos archivos y, sin dominar el derecho procesal, cualquiera los reconoce como una farsa con burda apariencia de legalidad. Por consiguiente y desde un enfoque de retórica judicial en la fase de Intellectio, se puede considerar el voluminoso expediente como prueba no técnica para sostener algo que José Mejuto Bernárdez seguramente pensaba pero no podía en ese momento alegar: que el status de la causa en la que quedaron encartados él y los otros acusados que lo acompañaban, se podría haber tomado como un conflicto de traslación, "consistente en la impugnación de la legalidad" de la acción judicial misma: (Lausberg 1975: 125-126, 148-149, 183). Lo cierto es que su inculpación lo fue en un conflicto de conjetura (¿participó en los sucesos de Cangas?) que luego fue derivando hacia un conflicto de cualidad por las agravantes que cayeron sobre él (¿huyó después de participar y mover a otros por sus ideas comunistas, como hizo en el 34, con disimulo y ocultación?) (Ibid. 131-132, 158, 167).

La autoría de los expedientes es colectiva. Fueron obra de un emisor casi multitudinario y por lo tanto, difuminado. Como discurso social, empleando términos bajtinianos, es fundamentalmente monológico, concentrado en quien ostenta el poder de la ley, el juez castrense. Las voces de los procesados y de los testigos se citan en estilo indirecto, como es propio del lenguaje jurídico administrativo. La mayoría de ellos declara en contra de los reos, así que las pocas voces discordantes que aparecen excepcionalmente pueden cobrar nueva intensidad dialógica a la luz del contraste con textos de memoria superviviente, como son las cartas de Mejuto.

\section{Lectura del proceso en el Expediente del Consejo de Guerra y en las cartas de José Mejuto Bernárdez ${ }^{4}$}

Las cartas que se han conservado -hay indicios en ellas de que Mejuto debió de escribir unas cuantas más- muestran la ignorancia del preso durante los primeros meses acerca del proceso en el que se ve incurso. Eso supone, de acuerdo con la retórica del género judicial, el desequilibrio dialéctico entre acusación y defensa en las ocasiones en que a Mejuto se le hace declarar ante un juez (Ibid. 111). Aun así, y contrariamente a lo que hace el protagonista de la famosa novela de Franz Kafka, El proceso (1925), él se niega a renunciar públicamente a su inocencia.

Aunque la intuye durante los meses precedentes, no es consciente durante mucho tiempo de la gravedad de los cargos, pues solo se los comunican cuando está a las puertas de un consejo de guerra. Las cartas, en esa primera fase, aluden pocas veces a asuntos de declaraciones y traslados. José Mejuto prefiere hablar de amor y promesas de libertad futura a su mujer, su madre, su hermana..., y distraerlas con peticiones y comentarios de intendencia. Cuando lo sentencien a muerte ocho meses después de su detención y esté esperando otros dos más a que un día lo lleven a matar, solo entonces escribirá largamente, para reconstruir la pesadilla vivida desde aquella madrugada. Lo hará en dos fases: en una carta-testamento para sus hijos, fechada el 24 de mayo, cuando imaginaba que muy pronto lo ejecutarían. Y en una larga sucesión epistolar entre el 3 y el 16 de julio, amplificando lo que ya les había contado sucintamente. La narración meticulosa será su respuesta a la doble cuestión de cómo perdió la libertad y cómo fue condenado a muerte (Mejuto Bernárdez 2015: 164). La

4 Cuando se haga cita del Expediente de la Causa 790/36 se indicará el número de folio y, en su caso, el reverso. (VV. AA. 1936 y ss.) 
emplea como prueba de inocencia para que sus hijos la conozcan cuando crezcan y la puedan poner en relación con otros crímenes, tal como los libros de historia - piensa él- reflejarán en un futuro no lejano:

Hijos míos: a veces pienso, y con razón, que cuando lleguéis a mayores, y penséis y discurráis por cuenta propia, os preguntaréis: ¿qué delito habrá cometido nuestro padre para que le hayan condenado a tan terrible condena como es la pena de muerte? Cuando a esa edad hayáis llegado, ya estarán consignados en la historia estos episodios trágicos que ensangrientan a España en estos momentos; y en ella podréis leerlos, mucho mejor explicados de lo que yo puedo hacerlo. Pero, no obstante, voy a daros una ligerísima idea para que sepáis por qué vuestro padre ha llegado a este triste fin. ("Día 3 de julio", Ibid. 155)

En efecto, suponía que sus hijos se cuestionarían las causas de la condena de su padre pues el asunto despertaría dudas en ellos cuando conocieran su final (Lausberg 1975: 106). Era este su último alegato de inocencia, el más importante para él, pues lo dirigía a sus hijos. Había tratado ya de defenderse sin éxito ante un tribunal militar, un consejo de guerra, como se ha visto, fuera de la ley dimanada del estado democrático que el ejército golpista pretendía deshacer. Se había sometido a este tribunal, confiado en poder demostrar esa inocencia, y había terminado por comprobar que era un mero instrumento para cometer crímenes de guerra asegurándose la impunidad en la nueva etapa histórica.

\section{La doble narración del proceso}

En el Expediente de la causa, la narratio tiene una única función: la exposición de los hechos conectada con la acumulación de pruebas sobre las que basará la argumentatio posterior: una argumentación cuyas premisas de partida son inamovibles pues están sujetas a los soportes ideológicos de los golpistas en guerra. Salvo en contados momentos en que parece haber un intento de justificación de lo afirmado con argumentos de persona-identificada con el colectivo del ejército-, predomina el logos y están ausentes el ethos y el pathos (Meyer 1999: 15-16). Un ejemplo ilustrativo de esta excepción es el primer Resultando de la sentencia condenatoria del 12 de mayo de 1937. En él, se halla la probatio a favor de un proceso judicial que el juez considera justo y necesario.
Ese argumento, que se repite con variantes a lo largo del proceso, termina con la conclusión de que se puede condenar a los reos por un delito de "rebelión militar":

Resultando: Que al iniciarse el 17 de julio de 1936, el Movimiento Nacional que está salvando a España por el cual el Ejército se hizo cargo del Poder Público que venía detentando el Gobierno del Frente Popular, ilegítimo en su origen, por proceder de elecciones falseadas y sobre todo por el ejercicio hecho de la Autoridad al poner ésta al servicio de organizaciones revolucionarias que venían destruyendo los principios fundamentales de la nacionalidad Española, contra las Autoridades Militares, únicas legítimas, ya que cumplían uno de los fines primordiales del Ejército, cual es de librar a la Patria de los enemigos exteriores e interiores, se alzaron grandes contingentes de enemigos armados que dirigidos por Jefes Militares traidores a España, aun hostilizan al Ejército en algunas zonas del Territorio Nacional. (VV.AA 1936 y ss.: 251)

En cambio, las cartas de Mejuto usan la narración de dos maneras. Primero, como narratio retórica, es decir, exposición de lo vivido en julio de 1936, su detención dos meses después y finalmente, su condena a muerte. Como introducción a estos hechos, explica las circunstancias ideológicas e históricas en que se producen, con evidente intención didáctica y valor de premisa general de la que se va a extraer una conclusión particular: lo injusto de su propio proceso. Expuestos así, los hijos sabrán cómo y por qué fueron sucediendo las cosas. Se sitúa el discurso en un ámbito de predominio de la base argumentativa posterior: el logos.

En segundo lugar, aparece la narratio como prueba que la retórica denomina exemplum, esto es, argumentación consistente en la narración de casos concretos para, a través de una inferencia inductiva, concluir en una idea general. Mejuto narra los episodios destacados de su vida para apoyar la tesis de su defensa. Ya es reo de muerte y lleva a cabo ese relato autobiográfico familiar para que sus descendientes conozcan su origen, formación, ocupaciones, relaciones, manera de ser y sentimientos. Con ello quiere transmitir a los hijos el sentido ético de su existencia. Como se puede ver, el discurso se sitúa en un ámbito de predominio de argumentación del ethos. 
Junto al carácter y la palabra argumentativa, el hilo vertebrador en estas dos funciones de la narración es el pathos, por tratarse de comunicación epistolar dirigida a destinatarios concretos. Como se vio más arriba, piensa el autor de las cartas que los libros de historia harán la parte correspondiente a la conservación de la memoria pública. Por esa razón él no pretende publicidad fuera del mundo familiar, sino que lo narrado quede en la memoria y el entendimiento de los hijos. A este respecto y de manera muy distinta a la que se acaba de ver en la cita anterior, empieza argumentando Mejuto, con las palabras previas a la narratio, acerca de lo que los golpistas llaman Movimiento Nacional. El contraste ideológico es evidente:

El día 17 de julio de 1936 -pronto va a cumplirse un año-surgió en España un movimiento militar contra el Gobierno Republicano del Frente Popular. Pronto ese movimiento se extendió por toda España y al cabo de pocos días, después de cruentas luchas en las principales capitales y ciudades, lograron los militares vencer la resistencia de las masas populares en diversos pueblos y capitales de provincia, quedando estas sometidas a los militares.(...) Galicia entera quedó prontamente sometida, pues apenas hubo resistencia. Desde aquel momento, la libertad y la vida de las personas quedó a merced de los que en los pueblos y aldeas tenían influencia en la nueva situación creada, los cuales, aprovechando su situación de privilegio, vieron llegada la hora de ejercer, contra las personas que ellos quisieron, las más ruines venganzas personales. Y así ocurría, y está ocurriendo aún, que bastaba la más insignificante denuncia falsa, para que inmediatamente fuese encarcelada y procesada cualquier persona. ("Día 3 de julio", Mejuto Bernárdez 2015: 155-157)

Se han seleccionado algunos momentos del relato de la pérdida de la libertad y de la vida de Mejuto: el de su detención, el de la inopinada intervención posterior de los guardias municipales de Cangas como testigos de la acusación y el del fallo del tribunal militar. Complementándolos con datos necesarios para su contextualización, se podrá observar la doble perspectiva narrativa reproduciendo primero el expediente de la causa y a continuación, la escritura en la cárcel de José Mejuto en los días anteriores a su fusilamiento.

\section{Detención}

José Mejuto Bernárdez es detenido a las seis de la mañana del 20 de septiembre en el curso de una redada en Teis, Vigo. Ha habido un aviso y la guardia civil, acompañada de civiles voluntarios, está entrando en las casas para registrarlas ${ }^{5}$. Los guardias consideran sospechoso que Mejuto se haya ausentado de su domicilio y se lo llevan detenido. Con él van presos Ramón Rey Fernández y su hermano Manuel Rey Fernández, Serafín de Dios Rodríguez, José Lorenzo Martínez, Darío González Pazo y José Alonso Castiñeira. El primero servirá para dar nombre a la Causa que se incoa después, la $n^{\circ} 1077 / 36$.

En el cuartel de la Guardia Civil de TeisLavadores, esa madrugada José Mejuto hará una manifestación recogida en el siguiente atestado:

(...) en el domicilio del vecino de Manuela Veiga Couto, fue habido el que dijo llamarse José Mejuto Bernárdez, de treinta años de edad, casado, mecánico, natural y vecino del lugar de Forte, de la parroquia de Coiro, en el término municipal de Cangas, el que manifestó que el motivo de encontrarse en dicha casa, es por ser de la familia y haber venido ayer desde Cangas a Vigo a solucionar asuntos particulares y como perdió el último barco, tuvo necesidad de quedarse a dormir en el sitio donde se le encontró; agrega que él no ha intervenido para nada en los sucesos ocurridos desde que se declaró el Estado de Guerra, que en ese día estaba él en su domicilio y solamente salió a informarse de lo que ocurría, enterándose de lo sucedido, se marchó a su domicilio donde permaneció como de ordinario ${ }^{6}$. Que dejó de ir con frecuencia por Cangas quedándose en su domicilio y lugar por estar amenazado de muerte por un pleito que tuvo con unos convecinos $\mathrm{y}$ tener miedo a ser objeto de un atentado

5 Mejuto en su relato indica que eran "milicianos de la JAP" (Mejuto Bernárdez 2015: 160). Se trata de las siglas de la "Juventud de Acción Popular" de la CEDA, integradas por ultraderechistas.

6 En su declaración ratificatoria del 10 de octubre de 1936 ante el juez de Vigo Manuel Ariza, aclarará que fue el día 18 de julio, y no el 20, cuando salió de su domicilio a informarse de lo que ocurría (VV.AA. 1936 y ss.: 130v). 
personal, y que nunca perteneció a ningún partido político, ni tuvo actividades de ninguna clase, ni sociales ni políticas, sin que tenga más que decir. (VV.AA. 1936 y ss.: 130)

José Mejuto relatará a sus hijos este episodio, dando voz humana al guardia civil que lo detiene y al jefe del puesto de Teis:

En la noche del 19 al 20 de septiembre, quedé a dormir en esa casa, como os dije. Serían las seis de la mañana del día siguiente: 20 . Me desperté al ruido de unos golpes dados con violencia en la puerta de la calle. Se levantó el marido de mi prima, y preguntó desde dentro quién era. Con imperioso acento respondió una voz, desde afuera: “¡abran! ¡La autoridad!”. Entonces, le abrieron la puerta y entró un Guardia Civil, el cual, después de recorrer toda la casa, llegó hasta la habitación en que yo dormía, acompañado de mi prima, a la que le preguntó quién era yo (...).Yo le dije mi nombre. Entonces me dijo: "mire usted, yo no tengo orden de detenerle, toda vez que, si hemos venido a esta barriada, es para detener a varios individuos vecinos de aquí, contra los cuales hay orden de detención. ...Así que, como usted ve -me dijo, mostrándome una lista que tenía en la mano-, su nombre no figura en ella para nada. Pero la circunstancia de ser usted aquí desconocido, es lo que me mueve a detenerle. Así que queda detenido, ínterin no se aclare quién es usted (...)Ya en la calle, me reunieron con diez o doce detenidos más, todos ellos vecinos de aquel barrio. ("Día 3 de julio", Mejuto Bernárdez 2015: 159-160)

Mejuto espera en el local de la Sociedad de Agricultores de Teis a que la guardia civil reciba por teléfono noticias de Cangas sobre su persona. Lo cuenta dando de nuevo voz a un guardia civil, el jefe del puesto: "dentro de un poco pediré informes de usted por teléfono a Cangas. Y si esos informes son buenos, lo pongo inmediatamente en libertad" (Ibid. 160). Cuando llegan esos informes, le hacen saber que son desfavorables. Lo trasladan en tranvía - Ángela, su prima y más tarde su hermana Carmen, lo van acompañando- hasta el Frontón de Vigo, convertido en prisión. Allí lo introducen los falangistas que guardan las puertas: "Por primera vez en mi vida perdía la libertad" (Ibid. 163).

Todo esto lo ha relatado Mejuto con la atención hacia los detalles que solo puede tener un aficionado a la literatura. Y se dirige a sus hijos, presentes como destinatarios en todo momento: "Ya en la carretera, y de noche cerrada, vuestra tía nos seguía sollozando. Aquellos sollozos me partían el alma de dolor. Los guardias, compadecidos sin duda de ella, la permitieron que se cogiese de mi brazo" (Ibid. 162). Llama la atención la capacidad expresiva y el estilo cuidado de un mecánico cualificado y con estudios. Eso hace que las cartas alcancen una calidad literaria que las aproxima en muchos de sus pasajes a la tradición del género epistolar de la literatura argumentativa.

\section{Informe de la Guardia Civil de Can- gas con las declaraciones de tres guardias municipales}

Mediado el mes de octubre de 1936 se incoa en Vigo la Causa 1077/36, en la que se suceden tres jueces además del instructor previo: Manuel Lage Becerra, José Solís y Riestra, Manuel Ariza y Díez de Bulnes y Francisco Arriaza Seoane, todos ellos oficiales del ejército sublevado.

José Mejuto Bernárdez sigue encarcelado. En el curso del proceso indagatorio, el 11 de noviembre la Guarda Civil de Cangas envía un informe, después de ser solicitado por el juez, que va a ser determinante para el futuro del preso, pues además de dejar caer sobre él el sambenito del comunismo, asegura que estuvo encartado por los sucesos de 1934 y que ahora tres guardias municipales declaran que se encontraba en el escenario de los hechos producidos en Cangas los días 19 y 20 de julio de 1936. Se reproduce a continuación el informe transcrito literalmente en el expediente 790/36:

En cumplimiento a lo ordenado en su respetado y superior escrito de fecha siete del actual, tengo el honor de participar a V.S. que el vecino de la parroquia de Coiro, de esta demarcación, JOSÉ MEJUTO BERNÁRDEZ, de oficio mecánico, es un elemento de ideas comunistas muy destacado y alentador de masas, esquivando siempre su responsabilidad.- En los sucesos de Octubre de 1934, estuvo encartado, librándose de la acción de la justicia por los motivos expuestos anteriormente, de esquivar la responsabilidad.En los sucesos actuales, se sabe estuvo el día diecinueve en el Ayuntamiento, según manifiestan los guardias municipales Modesto García González, Manuel Miranda González y José Piñeiro, todo el día, siendo visto también venir del mismo a las cinco de la mañana del día veinte en unión de los maestros de Coiro, VICTOR SANCHEZ MARTIL (Fusilado) y VICENTE SAEZ RUIZ (detenido y procesado) para su casa, es de suponer cooperara a cuantas 
iniciativas se expusieron en aquel lugar para oponerse al Movimiento Nacional, toda vez que ya se había efectuado la requisa de armas por el Alcalde, que fue de la Comisión Gestora Don AGUSTIN JORGE ECHEVERRI (Fusilado), el citado día diecinueve, así como la idea de mandar gente armada a Pontevedra, esto viene a corroborar el hecho de que desde el momento que se declaró el Estado de Guerra huyó para Vigo en donde fue detenido el día veinte de Setiembre último (...) (VV. AA. 1936 y ss.: 131)

A continuación, se transcribe el registro de la declaración de Miranda en contra de Mejuto:

Declaración del testigo Manuel Miranda González. = En la villa de Cangas a trece de Diciembre de mil novecientos treinta y seis (...). = Preguntado diga si los días diecinueve y veinte de Julio próximo pasado, vió a JOSÉ MEJUTO BERNÁRDEZ, en el Ayuntamiento de Cangas, y qué hacía en él, dijo: Que el día diecinueve a la una o dos, sin que pueda recordar exactamente la hora, lo vio entrar en el Ayuntamiento en compañía de EMILIO NORES RODRÍGUEZ, hojalatero de Cangas, y GUMERSINDO JUSTINIANO, Maestro Nacional de Cimadevila, (Darbo), sin que sepa a qué iba; que el día veinte lo vio en el balcón del Ayuntamiento, en el momento en que salía una camioneta cargada con escopetas hacia Pontevedra. $=$ PREGUNTADO con qué carácter estaba en el Ayuntamiento el MEJUTO BERNÁRDEZ, y por qué lo dejó entrar en el mismo, dijo: que tenía orden del Alcalde de dejar entrar a los del Frente Popular, y como el dicente sabía que el MEJUTO BERNÁRDEZ, pertenecía a dicha coalicción (sic), por eso lo dejaba entrar. $=$ PREGUNTADO si sabe que el MEJUTO BERNÁRDEZ, hubiese intervenido en la requisa de armas o destribución (sic) de las mismas a los marxistas, dijo: Que por estar en el vestíbulo del Ayuntamiento, no puede decir si el JOSÉ MEJUTO BERNÁRDEZ, haya intervenido en la requisa de armas o distribución de las mismas a los paisanos. (Ibid. 131v)

Las declaraciones de los otros dos guardias son mucho más vagas y se supeditan a la de Miranda -a quien, además, uno de ellos cita-, en el sentido de que no agravan más la situación del mecánico. Las tres disienten en lo relativo a las compañías de Mejuto. Por otro lado, esos acompañantes que nombran son personas ya fusiladas, paseadas o que se buscan ahora para inculparlas en el proceso contra Echeverri. Un dato definitivo que hace dudar de la veracidad de lo que declaran es que, tal como se puede leer desde el principio del expediente, estos guardias municipales ya estuvieron declarando a propósito de otras personas encausadas en el proceso contra el alcalde de Cangas y en ninguna de sus intervenciones habían mencionado el nombre de José Mejuto Bernárdez.

Este, en sus cartas, anticipa estos testimonios e informes al comienzo de su narración epistolar del 16 de julio. Quiere partir de una refutatio general de las pruebas de la acusación antes de entrar en el relato de lo particular. En esta prolepsis narrativa menciona el nombre de Miranda como hombre de paja que sus enemigos terminan encontrando para rematar el trabajo sucio que ellos anónimamente han empezado:

Ahora os voy a narrar todo lo que sucedió más tarde para que me procesaran y condenaran a muerte. El primer propósito de mis enemigos fue conseguir que me detuviesen. Para ello dieron aquellos infames informes a la Guardia Civil y Delegado de Orden Público. Pero a ellos les interesaba algo más que el que estuviese detenido: su objetivo final era matarme. Así que, desde aquel momento dirigieron todos sus esfuerzos en buscar a cualquier desgraciado que formulase contra mí una denuncia falsa. Pues ellos no querían dar la cara, como hicieron con los informes que dieron a la Guardia Civil, en que esta no hizo constar de qué fuente procedían, o sea, que no dijo quiénes fueron las personas que confidencialmene le dieron dichos informes; así que los verdaderos inspiradores y autores de esos informes quedaron ocultos en la sombra. Pues bien, al cabo de un mes aproximadamente de estar preso en el Frontón de Vigo, pudieron encontrar esos enemigos míos-que más adelante os diré quiénes son- un miserable que se prestó a hacer contra mí una denuncia falsa. Este miserable es un guardia municipal de Cangas que se apellida Miranda (...) (“Día 16 de julio", Mejuto Bernárdez 2015: 170-171)

Párrafos después, en el relato espistolar que sigue una línea de sucesión cronológica, José Mejuto Bernárdez cuenta que no conoció lo que él llama "denuncia de Miranda", como tampoco supo del contenido de ningún informe, hasta el 21 de abril de 1937, día de la lectura ante los acusados del auto de procesamiento que firma José Solís y Riestra. Es curioso que también ahora mencione solo el nombre de Miranda y calle el de los otros dos municipales (¿los consideraría testigos a la fuerza?):

Al siguiente día, nos llevaron a todos al cuartel de artillería que era en donde estaba instalado 
el juzgado militar que instruía nuestra causa. Y allí (...) nos dieron lectura a todo el sumario. Fue entonces cuando me enteré de los informes que de mí dio la Guardia Civil y el alcalde o Delegado de Orden Público de Cangas, como también de la denuncia que contra mí hizo ese miserable guardia municipal llamado Miranda, cuyos informes y denuncia ya conocéis. Yo traté de demostrar que todos aquellos informes y denuncias que se me hacían eran falsos, y al efecto aporté pruebas. Mas todo fue inútil. (Ibid. 175)

\section{Más informes negativos e infructuosas declaraciones de los testigos de la defensa}

Si se retrocede unos meses, se podrá puntualizar cuáles fueron las claves de la estrategia para la condena irremisible del preso: el 16 de diciembre, tras varias declaraciones en las que este insiste en que no participó en los sucesos de 1934 ni de 1936, Manuel Blanco, inspector jefe de la Dirección General de Seguridad de Vigo (es decir, la policía política), informa a requerimiento del juez de un modo que va a resultar letal para José Mejuto: no solo por la calificación que hace de su persona, sino porque por su pasado sindicalista lo va a vincular por fin a los sucesos de 1934 que, como se comprobó, el ejército golpista y sus colaboradores están utilizando para deshacerse de elementos de ideología contraria:

José Mejuto estaba afiliado al Sindicato Metalúrgico, afecto a la U.G.T. (Casa del Pueblo), y aunque en la actualidad no desempeñaba cargo directivo, durante la última huelga que sostuvo dicho sindicato en Vigo, era Secretario del mismo y hombre de confianza del extremista Eduardo Araújo Conde ${ }^{7}$. Este individuo es un elemento extremista y peligroso. (VV.AA. 1936 y ss.: 132 vuelto)

Pocos días más tarde, el Gobernador Militar de Pontevedra, Leoncio Aspe, envía notificación de que Mejuto no está incurso en ningún proceso de jurisdicción militar. Pero aporta un nuevo informe que ha solicitado a la Comandancia de la Guardia Civil de Cangas. Se trata, pues de un segundo informe que será decisivo en este momento, pues carga aún más las tintas en el retrato de Mejuto como enemigo político ${ }^{8}$ :

Ha observado buena conducta, tanto en su vida pública como privada; es de ideología comunista; y en sus actividades político-sociales se ha destacado como un elemento propagandista de esta idea, si bien en todos los casos, alentó a los demás a cometer actos de violencia, quedándose oculto en la sombra del impunismo. En los sucesos de Octubre de 1934, estuvo complicado, si bien en igual forma que ahora, pero por ser hombre listo, sabe escudarse de la responsabilidad, pues durante los sucesos de Julio último, permaneció en el Ayuntamiento en unión de varios individuos que hoy se encuentran procesados, otros ejecutados y otros condenados, desapareciendo una vez se tomó el mando de esta Villa por la Autoridad militar. No cabe duda de que él, como los demás que estaban allí, fraguaron el plan de resistirse, toda vez que se acordó el reparto de armas, requisa de vehículos, construcción de bombas, y el envío a Pontevedra de gente armada. (Ibid. 133)

La trama va enredándose alrededor de Mejuto para no dejarlo escapar. Y le es difícil ya aclarar las responsabilidades. Surgen nuevas variantes de estos informes. Mejuto trató de tomar nota de todo durante la celebración del Consejo de Guerra:

(...) no puedo daros una referencia textual, sino aquello que conservo en la memoria. No obstante, en síntesis, eran como sigue: "que era un viejo dirigente alentador de masas. Que era muy inteligente y que mi actuación política no era pública, sino callada, rehuyendo siempre toda actuación pública. Que, debido a eso, no había dejado nunca rastro de mi labor política. Que ya había tomado una parte muy activa en el movimiento revolucionario de octubre del año

7 No hemos podido comprobar documentalmente si Mejuto fue, como se dice aquí, secretario de Eduardo Araújo Iglesias. Este obrero metalúrgico, afiliado al PCE desde 1931, tuvo importantes cargos en el Sindicato de la Unión Metalúrgica (UGT). Elegido compromisario representante del PCE en el Frente Popular para la provincia de Pontevedra, es declarado en rebeldía cinco días después de la firma de este informe, el 20 de diciembre de 1936. Morirá en 1938 en un enfrentamiento con las fuerzas del orden en Lavadores (Fernández 2005: 302, 651).

8 El informe alude a la petición de información el "20 del actual”, pero está firmado el 17 de diciembre. ¿Es un error de escritura o el informe se pidió el mes anterior porque el complot contra Mejuto se aceleraba? Mejuto siempre creyó que el informe era uno, y no dos, que son los que figuran en el expediente. 
1934 en Cangas y que con tal motivo estuve preso. Que no podían afirmar con certeza si había tomado parte en la resistencia contra el ejército, con motivo del levantamiento de este el día 18 y siguientes del mes de julio de 1936, pero que suponían que debí de tomar alguna parte, por ser amigo de los principales dirigentes del Frente Popular de Cangas. Y, finalmente, que era socialista.

Esto era, en sustancia, los informes que de mí dio la Guardia Civil. Como podréis observar, todo ello además de ser absurdo y contradictorio, es completamente falso. ("Día 10 de julio", Mejuto Bernárdez 2015: 166-167)

Irá refutando una a una las acusaciones de mayor a menor gravedad y terminará ironizando sobre la acusación, en unos informes, de ser socialista y en otros, de ser comunista, así como sobre la consideración de la inteligencia como agravante: "por lo que se ve, en este punto parece que no marchaban de acuerdo. (...) en ambos informes pusieron eso "de que yo era muy inteligente" (...) para esos señores el ser inteligente es un delito $\mathrm{y}$, como tal, tiene que ser castigado" (Ibid. 170).

En la declaración amplificatoria del 20 de diciembre de 1936, José Mejuto solicitaba que cinco testigos pudiesen confirmar que él había estado en su casa y en la finca de La Retirosa los días 19 y 20 de julio. Todos declaran en este sentido, menos un barbero al que se le nota el miedo en sus palabras desmemoriadas. Se dará paso a la voz -por aquello de la ruptura monológica en el expediente- de la vecina de O Forte, Josefa Rodríguez Alvariño, natural de Ferrol y de profesión sus labores. El 28 de diciembre le dice al juez, que se ha trasladado a Cangas para tomarles declaración:

(...) Que el día diecinueve, a eso de las ocho o nueve, sin poder precisar, vió (sic) bajar de su casa a JOSÉ MEJUTO BERNÁRDEZ, el cual se dirigió hacia Coiro, suponiendo la dicente que fuese a una finca que tiene en dicho lugar, que a eso de las doce, lo oyó andar por su casa, y aunque por la tarde no lo vió hasta eso de las nueve en que bajó a cerrar la puerta, lo oyó cantar y andar por el piso. $=$ Que el día veinte a eso de las diez, lo vió bajar y andar por los alrededores a distintas horas de la mañana -once y doce- y después lo vió en el piso a la hora de comer-sobre la una- por la tarde aunque no lo vio lo oyó cantar y andar por el piso, y a la hora de cerrar la puerta -nueve de la noche aproximadamente- charló un momento con la dicente y su esposo Ramón Tenreiro. (...) Que sí, que efectivamente, después del día veinte de Julio, lo continuó viendo hacer la vida normal. (VV.AA. 1936 y ss.: 134)

No pasa desapercibido a los lectores de las cartas el detalle de imaginar a José Mejuto cantando en casa a sus hijos. Aparece en una de las que escribe desde el campo de presos de la Illa de San Simón, el 4 de abril de 1937. Y se repite alguna vez más, como en la que escribe el 28 de junio en la prisión de Pontevedra. Es como si un nuevo argumento del ethos para su defensa surgiera de la lectura paralela de los dos documentos tantos años después:

Hoy es domingo. Aquí pasa desapercibido, es un día más, para mí no tiene aquella alegría de pasarme la mañana dominguera jugando con nuestros niños en casa y cantando con Fernandito. Hijos queridos, cuánto me acuerdo de vosotros, inocentes criaturas. (Mejuto Bernárdez 2015: 88)

¿Te acuerdas, cuando llegaba a casa todas las tardes, lo que gozaba cogiendo a nuestros hijos en mis brazos y cantándoles infinidad de coplas? El más aficionado a que le cantase era Fernandito, amigo, como yo le llamaba. Este tenía una verdadera pasión por mí: tan pronto entraba en casa ya no había medio de separarlo de mí. Y tenía que cantarle, tan acostumbrado estaba... (Ibid. 148)

Ese detalle queda grabado más que la mención que hace Mejuto a sus testigos en la siguiente cita:

(...) nombré a varios testigos, los cuales declararon que, tanto el día 19 como 20 de julio, me habían visto en mi casa del Forte, por habitar ellos el bajo de mi casa, y que habían hablado conmigo en mi casa a la hora en que se me atribuía que estuviera en el Ayuntamiento. También declararon varias personas que viven colindantes con la finca de "Retirosa", en conforme en aquellos días pasé buena parte de tiempo allí, como tenía por costumbre hacerlo siempre que mis ocupaciones me lo permitían. ("Día 16 de julio", Mejuto Bernárdez 2015: 170-171)

\section{Sentencia}

El 22 de abril, el juez eleva la causa al Auditor de Guerra, resumiendo los hechos e indicando los nombres de los encartados, al tiempo que saca de la lista los muertos, huidos y un enfermo internado en Conxo. El 1 de mayo se nombran defensores, pertenecientes al ejército, 
para la veintena de procesados. El grupo formado por José Mejuto, Gumersindo Gastiosoro Ruiz de Azúa, José Sanjuán Sansinenea y José Gallego Nogueira, va a ser defendido por el alférez de artillería Juan Astor García de Medrano.

En el relato del 6 de mayo del fiscal, alférez honorífico del Cuerpo Jurídico Militar, Alejandro García Vallesteros, se considera a Mejuto, como a la mayoría de los compañeros, culpable del delito en calidad de autor con el agravante de perversidad:

JOSÉ MEJUTO BERNÁRDEZ. Socialista y alentador de masas, ya estuvo comprometido el año 1934 cuando la anti-Patria hizo sus primeras armas. El día 19 y 20 de julio pasado los pasó en el Ayuntamiento colaborando con los dirigentes. El último día citado presenciaba desde el balcón de la Casa Consistorial la salida de una camioneta cargada con escopetas para Pontevedra. (VV.AA. 1936 y ss.: 207)

Para los veintiún reos se pide desde la pena de cadena perpetua a la de muerte, con exclusión de Evaristo Dobarro Landín, para quien se solicita la reclusión temporal (Ibid. 207v). El 10 de mayo se les lee el sumario. Es en ese momento cuando José Mejuto, como sus compañeros, se entera de todo el recorrido del proceso desde su detención.

El Consejo de Guerra comienza a las doce de la mañana del 12 de mayo en la Diputación Provincial, presidido por el teniente coronel de artillería Francisco Lorente Armesto. A pesar de las circunstancias, el defensor adjudicado al grupo va a cumplir un digno papel, pidiendo para todos sus defendidos la absolución.

A las cuatro de la tarde se escuchan las conclusiones del fiscal. Pide la pena de muerte para José Gallego Nogueira, José Meis Martínez, Germán Chapela Leiro, Ángel Martínez Fandiño y Agustín Sanjuán Sansinenea. Y para el resto de los acusados, "la imposición de la reclusión perpetua", a excepción del ya citado Evaristo Dobarro Landín, para quien solicita veinte años de reclusión (Ibid. 249v).

El tribunal queda reunido en secreto y horas después dicta sentencia. Se hace difícil seguir poniendo la lupa en José Mejuto al leer la sucesión de Resultandos, pues el sufrimiento es colectivo y entre los nombres de los condenados se establecen lazos de sangre. Aún así, se destaca lo siguiente:
Que en el pueblo de Cangas del Morrazo se formaron también grupos de rebeldes (...), siendo destacados miembros de este grupo subversivo: Antonio Fernández Fernández, socialista peligrosísimo organizador de cacheos y de la expedición a Pontevedra; Agustín Sanjuán Sansinenea, persona inteligente y presidente del Frente Popular, por lo que las órdenes emanadas del Ayuntamiento eran en gran parte inspiradas por él; José Gallego Nogueira, fundador del centro comunista, directivo de esta organización, que envenenó con sus propagandas la parroquia y coaccionó a otros procesados para que fabricasen bombas; José Mejuto Bernárdez, elemento directivo en algunas épocas en Vigo de un sindicato marxista y alentador en Cangas de los movimientos subversivos, a más de haber intervenido en la revolución de mil novecientos treinta y cuatro; y José Meis Martínez que si bien no consta que tuviera una intervención personal en los sucesos ni siquiera que se hallara en Cangas en los días de la iniciación del movimiento, los hechos allí realizados obedecieron en gran parte a su labor perniciosa y disolvente realizada como Maestro nacional.

Fallamos que debemos condenar y condenamos a los procesados Antonio Fernández Fernández, Agustín Sanjuán Sansinenea, José Gallego Nogueira, José Mejuto Bernárdez y José Meis Martínez a la pena de muerte. (Ibid. 251 y 251v)

Lo que para José Mejuto debió de ser un infierno, se convierte a través de su escritura en una experiencia que le sirvió para acrecentar su ya mencionado sentido ético de la existencia. Se comprueba en el relato de cómo vivió el cambio de pena impuesta:

(...) el día 12, ante un consejo de guerra, soy condenado a la pena de muerte en unión de cuatro compañeros de infortunio llamados: José Gallego Nogueira, Agustín Sanjuán Sansinenea, José Meis Martínez y Antonio Fernández Fernández, todos acusados por un llamado delito de rebelión en Cangas de Morrazo.(...) se celebró el Juicio o Consejo de Guerra sumarísimo, y en él fuimos condenados a la pena de muerte cinco; y los restantes, dos absueltos y el resto, unos a cadena perpetua y otros a quince años de reclusión. Como dato curioso, he de señalaros que durante la vista del juicio, el fiscal, en sus conclusiones definitivas, solicitó seis penas de muerte; y para los quince restantes, reclusión perpetua. Entre estas penas de reclusión perpetua figuraba yo, así que para mí no pidió el fiscal pena de muerte. Sin embargo, el tribunal en la deliberación acordó elevarme a mí la pena reclusión perpetua, que era la petición final, a pena de muerte; y a dos de los que el fiscal pedía la pena de muerte, acordó 
el tribunal: a uno, absolverlo; y al otro, rebajarle la pena a reclusión perpetua.

A las seis de la tarde terminó el juicio y nos trajeron a todos nuevamente para la cárcel. Mientras tanto, el tribunal quedaba deliberando, así que no se conocía aún la sentencia.

Ya en la cárcel, uno de los compañeros para el cual el fiscal pidiera la pena de muerte, lloraba amargamente. Yo, que siempre he sido tan sensible al dolor ajeno, le dirigía palabras llenas de consuelo y de esperanza, diciéndole que el tribunal quedaba deliberando y que sin duda alguna había de rebajar las penas pedidas por el fiscal. ¡Oh, paradoja! Eran las diez de la noche cuando vino el juez, y los defensores, a la cárcel a comunicar la sentencia del tribunal. Aquel compañero al que yo consolaba se salva de la pena de muerte y a mí me condenan a ella. (Ibid. 113, 175, 176)

Los presos son conducidos a la cárcel de Pontevedra, en la que permanecerán hasta no se sabe cuándo. Hasta que un día les digan lo que Mejuto esperaba que le comunicasen a él: "desde entonces, día a día, hora a hora, estoy esperando la muerte. Estoy esperando a que un día - ¿cuándo?- me digan: "Salga usted, que le vamos a matar" ("27 de junio", Mejuto Bernárdez 2015: 147).

\section{Conclusión}

Acaba de analizarse como "estudio de caso" el proceso del republicano condenado a muerte en 1937 en Pontevedra, José Mejuto Bernárdez, con un enfoque comparado y las herramientas de la Retórica renovada en los ss. XX y XXI por disciplinas como la teoría de la argumentación y la teoría de la literatura. Para completar el análisis, se ha recurrido a alguna noción proporcionada por la teoría del discurso social y la pragmática semiótica, tampoco ajenas al ámbito de aplicación retórico.

De esta manera, se ha tratado de diseccionar un conjunto de muestras textuales: por un lado, del Expediente de la causa en la que se juzgó al preso; y por otro, de la treintena de cartas que escribió durante los meses de encarcelamiento. Los textos pertenecen pues, al tramo comprendido entre el 20 de septiembre de 1936 y el 16 de julio de 1937, fecha esta que lleva la última carta escrita antes del fusilamiento del autor.

El análisis de muestras significativas de $n a-$ rratio o exposición de los hechos y de pruebas lógicas que utilizan la narración, los llamados exempla, concluye en que el uso y desarrollo de ambos recursos de la dispositio retórica solo se produce en los textos epistolares. En estos hay un predominio de los lugares y argumentos del ethos y el pathos que no impide la minuciosidad del detalle y la citación de otras voces discursivas para dotar de carácter casi literario a un relato que se erige en prueba de defensa por encima de todo. En el expediente, los argumentos de un ethos colectivo que es el del ejército sublevado se manifiesta especialmente en la premisa primera de la sentencia, después de irse insinuando en escritos con descalificaciones y proclamas que se unen a la copiosa y heterogénea documentación administrativo-judicial. La narratio en lo archivado es unívoca y no deja lugar a dudas para el camino que lleva a una sentencia tomada de antemano y sin ninguna garantía de legitimidad. Hay un fin pragmático de disfrazar de legalidad lo que es crimen de guerra. Predominan los lugares y argumentos del logos, con citación de pocas voces discordantes aunque temerosas: testigos de la defensa y militares en el ejercicio de abogados de aquellos que poca clemencia esperan.

El legado familiar que con sus cartas dejó José Mejuto se convirtió en 2015, al hacerse público, en discurso de memoria histórica. Se revela así como una metonimia de lo que la sublevación militar fascista hizo contra sus enemigos ideológicos, pues, como afirma Paul Ricoeur, "El testimonio constituye la estructura fundamental de transición entre la memoria y la historia". El hermeneuta francés señala también la vía para la conexión de los documentos de la memoria familiar y los documentos de archivo franquistas a los que se ha accedido, pues asegura que "El momento del archivo es el momento en que la operación historiográfica accede a la escritura. El archivo es escritura; es leído, consultado (...)" (Ricoeur 2005: 41, 218) ${ }^{10}$.

9 Esas palabras sirvieron de título al libro que Ana Paula Mejuto tenía preparado en 2009 y que, reconvertido, sirvió de punto de partida para la edición de las cartas de José Mejuto Bernárdez.

10 Se tuvo que solicitar (y han pasado cuarenta y un años desde la muerte de Franco) autorización al Ministerio de Defensa de España para consultar el expediente. 
Aun existiendo el peligro de que un enfoque tan preciso y concreto dejase el caso Mejuto aislado de su verdadero contexto -el del grupo de acusados que le acompañaron en la desgracia, así como el del masivo enjuiciamiento sumarísimo que el ejército golpista llevaba a cabo en Galicia y otras zonas de España-, se emprendió el estudio con la seguridad de que se iba a contribuir de manera pertinente a la tarea colectiva de recomponer los pedazos rotos de una historia acallada durante muchos años.

Pertinente y valiosa, pues el "caso Mejuto" ofrece unas características que es difícil, por no decir imposible, encontrar en ningún otro caso de la represión franquista en Galicia. No se conoce a ningún otro preso que explicara y relatara minuciosamente su proceso en cartas familiares. También es extraordinario el hecho de que esas cartas sobreviviesen en el ámbito familiar durante casi ochenta años $\mathrm{Y}$ que un día se convirtiesen en materia de memoria social y pudiesen cotejarse con el expediente del Consejo de guerra porque el preso había dejado escrita la referencia a la Causa: 790/1936. $\mathrm{Y}$, finalmente, puede considerarse poco común la azarosa circunstancia de que una nieta suya entrase en contacto con investigadores de la literatura y la escritura de la memoria del otro lado del Atlántico donde Mejuto había padecido esa experiencia.

De esta cadena de sucesos, algunos casuales, es responsable José Mejuto Bernárdez, el autor de la escritura de una de las memorias más conmovedoras, por su carga de fe en el futuro, que se puedan conocer.

\section{Referencias Bibliográficas}

Alonso Montero, Xesús (2009): Cartas de republicanos galegos condenados a morte (1936-1948). Vigo: Xerais.

_ (2015): "Prólogo para un epistolario singular en tiempos de guerra e injusticias: unas cuantas reflexiones", en J. Mejuto Bernárdez, Cartas de un condenado a muerte. Santiago: Alvarellos Editora, pp. 11-26.

El Metalúrgico. Órgano de la Federación de Obreros metalúrgicos y similares de España (1929-1936) (1932a): "Reunión del Comité Nacional de la Federación Sidero Metalúrgica celebrada el día 21 y siguientes del mes de febrero de 1932", marzo, pp. 2-5.

El Metalúrgico. Órgano de la Federación de Obreros metalúrgicos y similares de España (1929-1936) (1932b): "Federación Sidero-Metalúrgica de España" (de Pascual Tomás en el Boletín de la UGT), marzo, pp. 3-4.

El Pueblo Gallego (1930a): "Petición de mano", El Pueblo Gallego 27/08/1930, p. 2.

El Pueblo Gallego (1930b): “Una boda”, El Pueblo Gallego, 25/11/1930, p. 4.

Fernández, Carlos (2005): El general Franco. Un dictador en un tiempo de infamia. Barcelona: Crítica.

Lausberg, Heinrich (1975 [1960]), Manual de retórica literaria. Fundamentos de una ciencia de la literatura, vol. 1. Madrid: Gredos.

Mejuto Bernárdez, José (2015): Cartas de un condenado a muerte ("Palabras previas" de Eduardo Galeano, "Prólogo" de Xesús Alonso Montero, "Las palabras tienen la esencia de la luz" de Ana Paula Mejuto, "Cronología" y "Extracto del Expediente de la Causa" de Ana Paula Mejuto y Olivia Rodríguez González; edición al cuidado de Olivia Rodríguez González). Santiago: Alvarellos Editora.

Meyer, Michel (dir.) (1999): Histoire de la Rhétorique. Des grecs à nos jours. Paris: Librairie Générale Française.

Ricoeur, Paul (2005 [2000]): La memoria, la historia, el olvido. Madrid: Trotta

VV.AA. (1936 y ss.): Expediente de la Causa 790/1936 "Contra Agustín Jorge Echeverri”, $2{ }^{a}$ Pieza: "Contra Antonio Fernández Fernández y veinte más”, Archivo Intermedio Región Militar Noroeste, Ferrol. 